\title{
'Epistemologia prática' no campo da comunicação lugo Levisolo*
}

\begin{abstract}
RESUMO
O autor considera como espistemologia prática a análise da reprodução do conhecimento de uma área, considerando o processo de formaçäo como resultado dos graus relativos de acordo epistemológicos e teóricos. No caso da comunicação, existiriam dois problemas básicos: o da fronteira (identidade) e o da escolha de critérios para o desenvolvimento de teorias concorrentes na área da comunicação social. Salienta as propriedades de mosaico e profissional como essenciais para a área de comunicaçāo. A partir dessas referencias situa a discussão epistemológica, passando pelo problema do objeto teórico e a impossibilidade, por indistinção, de traçar fronteiras a partir dele. Desenvolve a idéia de ser a ansiedade epistemológica produto de anseios de reconhecimento e legitimidade, ao invés de problemas espistemológicos estritos. Aponta a vigência de um "enredo" que envolve os niveis de ensino e pesquisa na área e propōe algumas saidas: a aceitação da pós-graduação profissionalizante, a aceitação da área como processo organizacional de interesses, ao invés de epistemológico, e a aposta na organização prática como meio de alcançarmos acordos teóricos e metodológicos.

\footnotetext{
ABSTRACT

Analyzing the formative process as results of the relative degrees of epistemological and theoretical agreements, the author considers as practical epistemology the analysis of the reproduction of the knowledge in each field. In the case of communication. appear two basic problems: the one of the frontier (identity) and the one of choice of criteria for the development of concurrent theories in the field of social communication. The author emphasizes the mosaic and professional properties as essentials for the field of communication. From those points of view the author places the epistemological discussion as indistiction bearing the problems of the theoretical object and the impossibility in placing the frontiers from this theoretical object. The author develops the idea of the epistemological anxiety as being the product of expectances for recognition e legitimity, instead of stricts epistemological problems. The author points the existence and predominance of and "script" that includes the levels of education and research in the field of social communication and proposes some paths: the acceptance of professional graduate level courses, the acceptance of the field as an organizational process of interests, instead of epistemological, and the bet in practical organization as a path to achieve theoretical and methodological agreements.
}

Professor da Faculdade de Comunicação Social da UERJ. 
Creio que uma forma intrigante de pensar e formularmos questões para a epistemologia da comunicação seja a de partirmos da observação e análise dos currículos universitários de graduação e pósgraduação. A proposição parece banal. Tentarei mostrar ao longo de minha argumentação que não há banalidade nenhuma em partir desse ponto de vista é que sua praticidade pode esclarecer aspectos que desaparecem quando a discussão se carrega de apropriações epistemológicas generalizantes e, também, com a aparente especificidade de certos problemas da área. As epistemologias que denomino como generalizantes propõem critérios de corte ou demarcação entre o científico e não científico. ${ }^{\prime}$ A falsabilidade popperiana é um critério dessa natureza que dominou a discussão durante mais de meio século. Temos, por outro lado, a epistemologia de problemas específicos como, por exemplo, o tipo de testemunho que representa o trabalho de campo para a antropologia, embora essa discussão possa ser situada no campo geral do papel das "testemunhas em ciência". 2 No creio que sejam estes os problemas significativos hoje para a área de comunicação.

Há dois problemas que considero relevantes para a área de estudos da comunicação. O primeiro, é o da fronteira: quais argumentos 126 devem ser acionados para afirmarmos que determinada teoria ou pesquisa pertencem a área de comunicação? E, será que isso pode ser feito de forma demonstrativa ou apenas poderemos elaborar argumentações que influenciem decisões momentâneas sem criar acordos duradouros? Minha resposta será na direção de afirmar que apenas podemos argumentar para conseguirmos acordos situacionais cuja principal função é manter a unidade da área. O segundo, é o da aposta: quais critérios devem ser acionados para apostarmos no desenvolvimento de algumas das teorias concorrentes na área da comunicação? Colocarei, no final do trabalho, alguns sinais dos possíveis caminhos a serem transitados para não ficarmos impotentes diante dessas questões.

Olhando para os currículos creio que poderei criar uma intriga sobre ansiedade epistemológica. 'Epistemologia prática' significa centrar os olhares na prática dos participantes de um campo disciplinar muito mais do que em sua relação sujeito/objeto de conhecimento dos fenômenos que, supostamente, entram no seu campo de pesquisa. Uma das coisas que fazem os participantes de um campo é a de formar discípulos, novos membros para o campo socializados em suas tradições. 
Se esta tarefa não é realizada ou campo ou área disciplinar tende a desaparecer. A tarefa, é bom lembrar. é tanto intelectual como emocional e, a formação, é um tema obrigatório da filosofia da educação e, portanto, da filosofia da ciência. Desenvolvimento da ciência e educação científica são perspectivas de ação interdependentes.

Há dimensões do processo de formação que podem ser consideradas como indicadores do estado dos acordos epistemológicos e teóricos do campo disciplinar correspondente. Assim, por exemplo, o grau de manualização de um campo de formação pode ser tomado como indicador do grau de adesão ao paradigma dominante e às teorias que o expressam. O currículo de formação expressa, portanto, o grau dos acordos de uma área disciplinar: a maior grau de acordo. epistemológico e teórico, maior homogeneidade nacional e internacional dos currículos da área. ${ }^{3}$ A major dispersão comparativa dos conteúdos curriculares indica menor nível de acordo ou, se preferimos, podemos afirmar que a homogeneidade é um indicador de paradigmaticidade e a heterogeneidade indica a pré-paradigmaticiade. O maior ou menor acordo sobre o currículo depende expressal os acordos sobre as teorias, matrizes ou paradigmas. ${ }^{+}$Estes acordos, por sua vez. expressam os acordos epistemológicos, ainda que sejam baseados na "filosofia em estado prático dos cientistas". ". Esta filosofia pode ser suficiente, como a história da ciência demonstrou repetidas vezes, para o desenvolvimento de uma área disciplinar, sobretudo quando opera como na imagem kunhiana de modo convergente na solução de problemas ou propõe programas de investigação progressivos, no sentido desenvolvido por Lakatos, ao qual os cientistas aderem.

Dou alguns exemplos para ajudar no entendimento do que estou dizendo. Há pouca discussão sobre a epistemologia das matemáticas ou da física entre seus profissionais e mesmo nos eventos científicos que os agrupam. ${ }^{6}$ Habitualmente, as condições de conhecimento dessas disciplinas são criticadas e debatidas em encontros de filosofia ou epistemologia, raramente nos das próprias disciplinas. Creio que podemos guiarmos pelo axioma de que a maior discussão epistemológica num campo disciplinar menor grau de acordo sobre as condições de conhecimento, os problemas e os instrumentos conceptuais adequados para seu tratamento. Deslacar a discussão epistemológica implica situar-se em campos disciplinares onde há teorias concorrentes, falta de unidade, pre-paradigmaticidade, ausência de consenso sobre o objeto e os métodos, enfim, baixo grau de acordo epistemológico e teórico. ${ }^{7}$ 
A diferenças de constituição e dinâmica do campo disciplinar se expressa no currículo de formação. Um currículo de matemáticas é basicamente matemáticas, e as discussões sobre o que deve nele entrar ou ficar fora não são centrais, não são constitutivas, embora as diferenças possam expressar ênfases ou preferências na maior ou menor carga de conteúdos e de carga horária dada a um ramo das matemáticas, por exemplo. O maior ou menor tempo dedicado ao estudo da física na formação do matemático indica a relação que historicamente é concedida à presença da física no desenvolvimento das matemáticas, contudo, não incide significativamente sobre os acordos em torno das matemáticas que devem ser ensinadas e aprendidas. Coisa semelhante acontece com a física, onde matemáticas e física formam o núcleo duro, não negociável do currículo. No campo das ciências humanas, o currículo de história é basicamente história, embora possa ser discutida a importância a ser dada ao aprofundamento de determinados temas e enfoque da história e o grau de aprofundamento em disciplinas auxiliares. Há fortes acordo em termos de objeto de estudo, embora haja diferenças teóricas e metodológicas significativas. Há, implícita ou explicitamente, um reconhecimento das condições de conhecimento que definem os conhecimentos que devem ser aceitos. Um campo maduro se reconhece nos acordos que definem 128 seu chão e os expressa no currículo de formação.

Um campo consolidado se expressa em temos de um currículo disciplinar, formado por conteúdos do campo disciplinar e pelas linguagens usadas na elaboração das teorias. Assim, a física, por exemplo, significa um currículo de física e matemáticas. Um currículo de direito significa disciplinas de direito (constitucional, civil e penal, etc.) mais algumas disciplinas auxiliares ou contextualizadoras (sociologia do direito, psicologia do direito, filosofia do direito, etc.), ocupando lugar de destaque a linguagem específica do direito. Em oposição, campos não consolidados se expressam mediante currículos que denomino de mosaico. Voltarei adiante sobre as características do currículo mosaico em comunicação. ${ }^{8}$

O currículo, disciplinar ou mosaico, pode ser pensados sob o ponto de vista de sua intencionalidade ou finalidades. Solicito que se aceita uma distinção bastante elementar, de tipo ideal, entre currículos orientados academicamente e currículos orientados profissionalmente.

O currículo de tipo acadêmico tem com objetivo principal formar pessoas capazes de desenvolver e transmitir os conhecimentos do campo disciplinar. Assim, o currículo de matemáticas, física, história, sociologia 
ou biologia, quer formar pessoas capazes para desenvolver os conhecimentos e transmiti-los. Produção e transmissão de conhecimentos são seus valores orientadores. As figuras típicas que representam esses valores em termos de ocupação são as do pesquisador e professor, desenvolvimento e educação científica os campos de atividade.

O currículo de tipo profissional, por seu lado, pretende formar pessoas capazes de intervir na sociedade a partir do horizonte de inserção profissional específico. Domina na formação do médico, do engenheiro, do jornalista, do advogado, do relações públicas, do publicitário, do contador, do administrador de empresas, entre outros, a vontade de formar um profissional capaz de intervir para solucionar ou responder a demandas sociais. As figuras típicas que as representam são as de perito, experto ou especialista. São pessoas contratadas para resolver problemas de áreas de atividade social no campo privado ou das políticas públicas. ${ }^{?}$

A orientação do currículo, acadêmica ou profissional, é sempre uma questão de grau ou domínio. Um currículo de medicina, embora dominado pelo valor de formar um interventor no campo da saúde. pode pretender abrir espaço para a formação do pesquisador $\mathrm{em}$ fisiologia ou clínica médica, por exemplo. Um currículo de matemáticas abrir a possibilidade de formar o perito em estatística. Habitualmente os gestores que desenvolvem um currículo com aberturas, que os fazem ser diferentes do "típico", são conscientes de sua diferenças e sabem que estão escapando dos acordos de um campo disciplinar, estão realizando concessões para adequar a formação a demandas circunstancias do mercado ou regionais. Por outro lado, pessoas formadas em currículos acadêmicos podem redefinir sua trajetória em termos de perito; também pode ocorrer o contrário, formados em currículos profissionais podem redefinir sua trajetória em termos de investigador. Apesar destas excepcionalidades, creio que a classificação mantém sua utilidade, mesmo quando levamos em consideração seus desvios, pois estes são reconhecidos pelos atores enquanto tais. Os atores dizem coisas do tipo: "O nosso curso de medicina é excepcional, pois ele enfatiza muito a pesquisa, quando comparado com os outros cursos de medicina". "Eu sou uma excepção, me formei em física e passei a trabalhar no desenvolvimento de produtos na indústria, a maioria de meus colegas foram para a pós-graduação, para a pesquisa acadêmica e para a docência". ${ }^{10}$

Creio que se cruzarmos empiricamente ambas as distinções disciplinar e mosaico com acadêmico e profissional-teríamos uma 
associação entre currículo disciplinar e formação acadêmica, de um lado, e currículo mosaico e formação profissional do outro. Contudo, há excepções, direito, estatística e contabilidade, por exemplo, são profissionais porém acentuadamente disciplinares. Assim, há currículos profissionais que podem ser disciplinares, porém o contrário parece ser raro: currículos acadêmicos com definição mosaico. De fato, eu não encontro nenhum exemplo do último tipo que me convença.

Os currículos que são simultaneamente "disciplinar" e "profissional" resultaram de um processo histórico de depuração. No caso do direito, por exemplo, parece-me claro que ao longo da consolidação da atuação profissional e dos acordos, o currículo depurouse de conteúdos teológicos e filosóficos.

Observo, e considero que esta observação deve estar presente no leitor, que os epistemólogos profissionais tomam por objeto de reflexão os modos ou formas de conhecimento das áreas disciplinares: matemáticas, física, biologia, fisiologia, epidemiologia, história, sociologia e economia, entre outras. Não conheço trabalhos de epistemólogos profissionais que tomem por objeto a reflexão o conhecimento em serviço social, administração, contabilidade, educação física, nutrição, jornalismo, publicidade, relações públicas, enfim, sobre os campos

130 universitários orientados à formação de profissionais. De praxe, se há alguma reflexão epistemológica, ela é produzida internamente, pelos profissionais desses campos e, não raro, caracterizadas pela precariedade e com uma forte intencionalidade de produzir reconhecimento ou legitimidade. Tudo indica que os epistemólogos consideram os campos disciplinares de formação profissional pouco interessantes para a reflexão ou apenas dependentes dos conhecimentos formulados nas áreas disciplinares que eles analisam. (No caso do Brasil, muitos currículos profissionais são considerados como "ciências aplicadas" na nomenclatura do $\mathrm{CNPq}$ ).

Creio que se há algum objeto epistemológico de interesse nas áreas profissionais é uma possível "epistemologia da intervenção". No campo da intervenção profissional há três temas que são centrais e recorrentes: 1) o das funções ou papeis profissionais e os valores que os orientam (qual a função, os valores e objetivos do jornalismo?), 2) o dos procedimentos e técnicas que possibilitam sua realização e 3) o da relação ou coerência entre 1 e $2 .{ }^{11}$ O ponto 3 é particularmente significativo, porque procedimentos e técnicas eficientes podem ser antagônicos com os valores e objetivos que orientam a ação. Uma 
técnica automática de ensino pode, por exemplo, estar em oposição com o valor da autonomia que orienta a educação. Podemos usar procedimentos espúrios no jornalismo, compra ou roubo de informações, para denunciar o criminoso? De fato, uma epistemologia da intervenção ainda está a ser desenvolvida, embora existam elementos esparsos. As questões que importam para a atuação profissional escapam portanto ao domínio clássico da epistemologia. Na formação profissional palavras como ciência, científico, conhecimento científico, etc., operam como legitimadores sociais, derivando seu poder da "aplicação" de ciências já constituídas. ${ }^{2}$ Assim, falamos de ciências contábeis, por exemplo, coisa não muito diferente de falar de ciências da comunicação. Registro que não estou questionando a função social dos contadores nem a dos comunicadores sociais nem a dos administradores de empresá. Estou dizendo, a partir da formação, que não se entende o lugar específico da discussão epistemológica nos currículos orientados para a formação profissional.

Feitos alguns dos esclarecimentos que interessam, podemos olhar para o campo da formação em comunicação social.

Os currículos de comunicação social têm duas características principais imbricadas: são profissionalizante e mosaico.

O aspecto profissional é evidente na medida que. como grande parte dos novos cursos universitários, trata-se de converter ocupações em profissões. $\mathrm{O}$ aprendizado da ocupação realizou-se, e ainda se realiza embora decrescentemente, na prática da mesma. Sabemos que os jornalistas se formavam na redação dos jornais, por um processo não sistematizado de ensino-aprendizado em interação com habilidades e interesses e mediados por mecanismos não explícitos de avaliação e seleção. As ocupações operavam sem proteção legal, embora existissem regulações corporativas, mediante a organização em associações $\mathrm{e}$ sindicatos que limitam a participação a seus membros. Em contrapartida, hoje o aprendizado da profissão se realiza crescentemente nas instituições de ensino, mediante processos formalizados (do currículo, da prática ou estágio, da avaliação, etc.).

As profissões, geralmente no Brasil, operam com proteção legal, exigindo tanto a titulação quanto o reconhecimento pelo organismo profissional (ordem, colégio ou organização semelhante). A proteção legal resulta da ação dos profissionais que procuram regulação e proteção para suas atividades. ${ }^{13}$ Importa destacar que a tendência a transformar ocupações em profissões implicou a multiplicação dos cursos de ensino 
superior e suas especializações, fazendo das universidades lugares nos quais se pode aprender desde filosofia e física até modas e gastronomia. $\mathrm{Na}$ área da comunicação, em particular, temos profissões como jornalismo, relações públicas, publicidade, marketing e outros. Trata-se sempre da formação profissional do perito, do experto, do especialista, enfim, do profissional no processo mais geral de justificação da utilidade do ensino superior para o mercado público e privado.

$O$ aspecto mosaico parece evidente quando consideramos que se desenvolvem conteúdos que podem ir desde filosofia do conhecimento até a elaboração de uma matéria para o jornal. Devemos reter, então, que a intencionalidade profissional marca o currículo, produzindo tanto a seleção dos conteúdos quanto o modo de seu desenvolvimento. As disciplinas do currículo podem ser agrupadas em três grandes subconjuntos.

O primeiro, que me permito de chamar de formação cultural, abrange disciplinas de outros campos, como filosofia, sociologia, psicologia, psicologia social, economia, história, lingüística e estatística, entre outras, e tem por intenção criar uma base de conhecimentos considerados necessários ou significativos para operar com o campo dos fenômenos comunicacionais. Há currículos que tendem a impor a "aplicação" dessas 132 disciplinadas ao campo da comunicação e a seus problemas. ${ }^{14}$ Assim, por exemplo, a sociologia é entendida como sociologia da comunicação e a psicologia como psicologia da comunicação. Este entendimentoé forçado pela perspectiva profissionalizante e apresenta alguns problemas. Forçado pela perspectiva profissionalizante por se entender que deve ser ensinado aquilo que tem vínculo claro e distinto com a formação profissional, que deve estar a seu serviço. Assim, há uma forte tendência em se ensinar e aprender aquilo que se entende como "aplicação" ou a "parte" sem o necessário conhecimento da fundamentação ou do geral. A sociologia pode; então, ser apenas sociologia da comunicação, e assim por diante. $\mathrm{Na}$ dinâmica escolar, os conteúdos de fundamentação e gerais — sem vínculos claros, embora imaginados, com a formação profissional— não raro são contestados por serem sem utilidade ou mera perda de tempo. ${ }^{15}$

O segundo subconjunto, que denominarei de formação básica do campo disciplinar, orienta-se a transmitir conhecimentos sobre dimensões ou problemas da comunicação. Entretanto, esse conjunto de conhecimento aparece, prima facie, como aplicação dos conceitos e instrumentos desenvolvidos em campos disciplinares mais tradicionais e, de praxe, dentro da listagem das disciplinas que entram na formação 
cultural. Habitualmente temos neste subconjunto disciplinas 'icónicas' como Teoria da Comunicação e disciplinas que produzem a junção entre comunicação e outra área disciplinar ou de fenômenos. como Comunicação e Política. ${ }^{16}$

Por último, o terceiro subconjunto agrupa as disciplinas que tencionam formar para a realização de uma atividade ou função a ser realizada no seio da produção de comunicações nos meios de comunicação ou nas empresas. Trata-se de transmitir a experiência sistematizada de como fazer o jornal. a campanha publicitária. o programa de rádio, a organização de um evento, a comunicação na empresa ou com scu público, enfim, trata-se de aprender a fazer aquilo que faz funcionar meios e empresas. O que habitualmente está sendo transmitido é um conhecimento prático. de procedimentos e técnicas. destilado pela prática de uma família tecnológica. Aquilo que se aprendia a-sistematicamente na ocupação passa a ser de diferentes formas sistematizado e transmitido, se possivel de forma prática, por exemplo. recriando oficinas de produção dentro dos cursos universitários. A escola imita o mundo do trabalho. se:ndo uma prova clara do caráter ou vontade profissionalizantc. Agrega, talvez, maior rigor no processo de seleção de procedimentos e técnicas eficientes. usando recursos padronizados de metodologias de pesquisa para seu controle.

A sociedade está interessada em que os peritos ou especialistas solucionem problemas, façam que as coisas funcionem. O fato de não podermos explicar o mecanismo de funcionamento de uma droga não impede que a usemos se ela é eficiente no tratamento de certas doenças. Não creio que um científico militante se negue a realizar massagens que aliviam suas dores de coluna porque não há uma teoria dos efeitos da massagem. Não criticaríamos uma obra de teatro que nos emociona por não sabermos o "como" faz isso. Não perguntamos a nosso contador qual é a base "científica" das opções que realizou para a declaração do imposto de renda. Se o administrador nos oferece um novo modelo não the perguntamos sobre sua validade epistemológica. porém sobre as experiências realizadas por outros e seus resultados. Sempre usamos conhecimentos derivados e destilados pela experiência embora não fossem científicos. Accitamos os peritos e especialistas e seus conhecimentos práticos e familiares como úteis e mesmo necessários.

O panorama apresentado permite afirmar que se existem problemas epistemológicos eles dizem a respeito das áreas disciplinares que participam do currículo mosaico, quer mediante suas teorias gerais. 
quer por meio da aplicação para os fenômenos comunicacionais. Assim, por exemplo, a validade das teorias da dita escola de Frankfurt, de alta penetração na comunicação, apresentam questões epistemológicas que são da filosofia e das ciências sociais, não do campo da comunicação. $\mathrm{O}$ mesmo poderíamos argumenta em relação aos problemas de conhecimento da linguística, da semiologia, a antropologia e suas teorias da cultura, da filosofia e especialmente da ética, entre outras. Nesses campos disciplinares se colocam as questões sobre o objeto, sobre as condições de conhecimento, sobre as relações dos dados com as teorias, entre outras.

Podemos então perguntar: como surge a discussão epistemológica no campo da comunicação. Mesmo, porque surge uma certa ansiedade epistemológica no campo da comunicação?

Conservando meu princípio de análise, deslocarei o olhar para a formação de pós-graduação, mestrado e doutorado.

A estrutura da pós-graduação no Brasil desenvolveu-se sob um enfoque abertamente acadêmico. Sua função foi, e ainda é, a de produção de conhecimentos e a formação do pesquisador e do professor. Este último objetivo sempre foi mais formal que real, dado que a maioria das pósgraduações não implementaram políticas de formação docente. As primeiras pós-graduações foram disciplinares e acadêmicas, mais tarde entrariam áreas de tipo mosaico e profissionalizante. Entretanto, na medida que entravam no sistema de ciência e técnica nacional, tinham que assumir os objetivos da pesquisa e da formação do pesquisador. Esse processo iniciado nos anos setenta acelerou-se nos oitenta.

Nos anos setenta creio que consolidou-se o acordo de que uma atividade científica de pesquisa tinha que ter teoria e esta seu objeto teórico definido. A ansiedade pela teoria e seu objeto se espraiou pelas pós-graduações nascidas de cursos profissionalizantes, como administração, serviço social e comunicação. O problema era simples em sua formulação: como considerar como científica áreas que não detêm teorias e objetos definidos e aceitos enquanto tais pelos acordos da área? Deixou de ser suficiente dizer que a física estuda a a natureza ou a matéria e que a sociologia estuda a sociedade. No caso da sociologia, a defesa do "fato social", da "ação social", da "interação social" ou do "modo de produção", indicava a teoria e seu objeto. A educação chegou a afirmar, pressionada pela ansiedade do objeto, que o seu era o "ato pedagógico" e a comunicação poderia afirmar seu "ato comunicacional". As opções de fato não satisfizeram. Apenas 
para mencionar alguns dos problemas, é obvio que não podemos pensar interação social sem comunicação nem comunicação sem interação social. Se partirmos do princípio de que existem dois tipos de comunicação, face a face e mediada, e se dizermos que a pesquisal em comunicação se encarrega das formas mediadas. temos um universo enorme e uma vontade de domínio considerável. Assim, no caso, se torna quase impossível distinguir o objeto da sociologia e da comunicação e toda teoria da interação deve ser uma teoria da comunicação e vice-versa. É impossível estudar o "ato pedagógico" sem uma definição normativa, pois ele se situa dentro da paideia, bildung ou formação. O "ato pedagógico" está determinado pelas concepções do justo, do belo e do verdadeiro, portanto pouca ou nenhuma autonomia tem enquanto objeto do filosofar sobre a educação.

A ansiedade epistemológica se manifestou na reações à última avaliação da CAPES (triênio 1998/2000). Coordenadores de programas tradicionais de pós-graduação de área discordaram da avaliação e atacaram os critérios ou "navalha epistemológica" utilizados pela comissão de avaliação da área. ${ }^{17}$ Segundo esses coordenadores. a avaliação teria privilegiado os programas onde o "conceito de comunicação está construído de acordo com a idéia de comunicação stricto sensu, prejudicando programas que optam por enfoques mais interdisciplinares" ( $p: 1) .^{18}$ "A referida navalha epistemológica não respeitou o critério fundamental que deveria nortear o processo avaliativo, qual seja, a liberdade de cada programa de definir, uma vez assegurado o compromisso fundamental com a área da comunicação. os limites de sua ambição epistemológica" (p:2, sublinhados H.L.). "O tema mais sério, entretanto, é o do conceito de comunicação construido pelos avaliadores para definir a área" ( $p: 2$ ). "A comissão mais rigorosa que o resto da área, impôs um consenso e o chamou de autocompreensivo.... O consenso não está construído na área. pelo menos da forma apresentada, e não há essa autocompreensão que faça concordar todos os envolvidos na discussão, mesmo aqueles expurgados na atual avaliação como estando fora do sistema" (p:3). "A comunicação não se resume à disciplina dos estudos de mídia, ainda que estes sejam, na origem, os marcos fundadores da área..." (p:4).19

Recuando em relação ao debate corresponde perguntar-nos: porque a Comissão de Avaliação assumiu a responsabilidade de operar com uma navalha epistemológica, não para distinguir entre sentenças científica e não científica, mas para separar o que deve e não deve estar 
dentro da área da comunicação? Porque guiado por essa intencionalidade tomou a definição consensual de dentro e de fora da área para definir o conjunto de fenômenos e objetos que constituiriam o campo?

Apostaria em que devemos procurar a resposta na pressão por igualação em termos de reconhecimento e legitimidade com as áreas acadêmicas tradicionais. Dado que é impossivel apontar para um pequeno conjunto de teorias e objetos que expressem o acordo sobre o que é comunicação, a Comissão deslizou para o reconhecimento empírico de fenômenos e objetos (os meios de comunicação, a comunicação mediada e, portanto, de reconhecimento social que entende que a física estuda o físico, a química o químico e a comunicação a comunicação mediada) que parecem não serem questionados a nível das representações sociais. ${ }^{20} \mathrm{O}$ acordo em termos de teoria significa que o recorte deveria ser feito pelo ponto de vista, pela estrutura conceptual que organiza os programas de pesquisa, pela teoria, e isso não ocorre quando entendemos a comunicação apenas como tendo por objeto a comunicação mediada. Não temos, de fato, acordos quando pretendemos sair da definição do consenso, a comunicação mediada, e irmos na direção do recorte teórico dos objetos da comunicação que, por essa razão, podem também ser matéria de estudo de todos as pós-graduações de ciências sociais e humanas. ${ }^{21}$ (Um estudo sobre a reação hormonal dos espectadores de um filme não forma parte do campo da comunicação, deveria estar na área da fisiologia ou psico-fisiologia. Os "hormônios" formam parte do aparelho conceptual da fisio-química, não da comunicação. O custo os impactos publicitários forma parte da administração econômica da publicidade, não necessariamente da comunicação, e são vistos sobre a ótica dos conceitos e instrumentos da economia. Os exemplos são inúmeros).

A comissão de avaliação diante das pressões e da vontade de reconhecimento e legitimidade optou pelo consenso social e pela tradição que enfatiza os estudos da mídia que, embora sejam bons passaportes de circulação, não podem validamente ser pensados nem usados como navalha epistemológica, pois a) se confundem com os objetos de outras disciplinas e b) os conceitos e instrumentos postos em jogo para os estudos da mídia são tomados da sociologia, da lingúística, da semiologia, da psicologia, da psicologia social, de teoria crítica, da análise do discurso, da teoria literária e imaginário e de tantas outras disciplinas e escolas que são de domínio público. A navalha apenas distingue para os não especialistas fronteiras muito frouxas, mal organizadas e de baixo controle que leva, no caso da exclusão, ao sentimento de arbitrariedade. 
Se entra qualquer coisa que tem a ver com a mídia. porque nós ficamos de fora, dizem os reclamantes?

Os enredos e as intrigas se montam em contextos institucionais. Para entendermos o enredo da comunicação temos que considerar que: 1) a área é profissionalizante na graduação. objetivando à formação de peritos ou expertos e dominada por as tradições técnicas familiares que se expressam em currículos mosaico com as características acima apontadas; 2) a comunicação tonou-se acadêmica a nível da pósgraduação, conseguindo autonomia institucional relativa. pois foi situada dentro das ciências sociais aplicadas sem que existam acordos sobre teorias, instrumentos conceituais e objetos; 3) a vontade de reconhecimento e legitimação força na direção de elaborar justificações de cientificidade e para isso se recorre a noções epistemológicas generalizantes ou a suposta especificidade dos fenômenos do campo a partir da representação social de impossível aceitação. porque a navalha com ela elaborada faz apenas de conta que corta e separa.

A saída é desmontar o cnredo mediante conversas que gerem acordos. Creio que deveríamos dar um passo significativo em reconhecer a vontade de formação dos peritos ou expertos e criarmos pós-graduações profissionalizantes, orientadas para a inovação em termos de processos e produtos para a comunicação mediada. onde a pesquisa desempenhe un papel de mediação para se atingirem os objetivos. Se fizermos isso. algumas das nuvens deixarão de dar sombras. Em segundo lugar. creio que deveríamos afirmar que as pós-graduações de comunicação são apenas um modo prático, artificial e institucional, de organizar portadores de diferentes conhecimentos disciplinares interessados em estudar o campo da comunicação mediada." Creio que temos alguns argumentos bons. embora não definitos, para dizermos: a tradição da área da comunicação ć a de fazer dialogar matrizes disciplinares, não vemos porque teríamos que abandonar essa tradição. Reconhecendo, no entanto, que estudos semelhantes podem ser realizados em outras áreas disciplinares ou pósgraduações acadêmicas. Reconhecendo, então, que não se trata de nenhuma navalha epistemológica. apenas de criar artifícios, redes de trocas, para que os interessados nas pesquisas em comunicação interajam c se comuniquem mediante estruturas organizacionais. Em terceiro lugar, reconhecer que estamos apostando em que a organização prática possibilite que cheguemos, talvez algum dia, a acordos sobre as teorias e os objetos. $E$, neste sentido, creio que deveríamos apostar nas teorizações que ao invés de enfatizar aquilo que a comunicação faz com as pessoas (classes. 
segmentos, grupos, entre outras categorias possíveis de agregação) trabalham na direção de compreender o que as pessoas fazem com aquilo que a mídia faz com eles. Eu apostaria nesta direção.

\section{Notas:}

${ }^{1}$ Ver Lakatos, I., História da ciência e suas reconstruções racionais, Edições 70, Lisboa, 1998 (1978).

${ }^{2}$ Ver as contribuições de Stengers, I., Quem tem medo da ciência?Ciência de Poderes, Edições Siciliano, Rio de Janeiro, 1990.

${ }^{3}$ Creio que os acordos são constitutivos do poder de uma área disciplinar o ciência. A forma e força do poder resulta da união que depende, no caso das ciências, dos argumentos que a produzem. Os argumentos fortes se tornam, por assim dizer, regras do jogo que os participantes da área devem respeitar. Os argumentos coagem, no sentido de Durkheim.

${ }^{4}$ Valha uma experiência. Na FCS da UERJ faz aproximadamente dez anos que se discute uma reforma curricular da graduação. Os obstáculos para estabelecer acordos parecem ser infinitos e são provocados pela vontade de especialização na formação dos peritos ou expertos. Assim, há uma tremenda pressão para que o currículo não estritamente profissional seja reduzido. Contudo, a vontade de reconhecimento do profissional como "científico" leva a criticar a formação do perito ou experto em cursos de curta duração e sem investimentos "teóricos". Creio que a tensão, entre a demanda profissional e acadêmica ou científica, sem solução evidente e com argumentações que não definem qual opção realizar, leva a impasses na reforma curricular. Além, por certo, dos cálculos dos envolvidos em termos de tamanho e significado do pedaço do bolo para cada que qualquer reforma curricular realiza.

${ }^{5}$ A frase entre aspas forma parte do arcabouço conceptual de Bachelard.

${ }^{6}$ As matemáticas parecem não se ressentir do fato de não estarmos de acordo sobre se podem ou não ser considerada uma ciência em pé de igualdade com a física, por exemplo. O seu caráter ambíguo, entre o meramente formal e o empírico, não parece afetar nem seu desenvolvimento nem o reconhecimento do valor específico dos matemáticos.

${ }^{7}$ As incidências das formulações de Kuhn são aqui evidentes.

${ }^{8}$ Uma discussão ampliada sobre a distinção disciplinar /mosaico pode ser vista em Lovisolo, H., Educação física: arte da mediação, Ed. Sprint, Rio de Janeiro, 1995. 
${ }^{9}$ Para uma análise mais detalhada das relações entre a orientação acadêmica e a da intervenção ver Lovisolo, H., Vizinhos distantes: universidade e ciência na Argentina e no Brasil, Ed. UERJ, Rio de Janeiro, 2000. No plano da intervenção é indispensável a distinção entre o perito ou experto e o intervencionista cientificista que pretende revolucionar a sociedade a partir da ciência. ver capítulos 3 e 4.

${ }^{10}$ As falas citadas formam pare do meu material de pesquisa sobre comunidades científicas. Parte desse material, e em algum sentido as próprias categorias que estou usando, podem ser conferidas em Lovisolo. 2000 .

"Estas questões são de difícil senão impossível discussão se excluirmos a tradição específica de cada família de intervenção. Estou me apropriando da expressão de Basalla, G., The evolution of technology, Cambridge University Press, 1988.

12 No campo da comunicação, como em outros campos profissionalizantes, domina espontaneamente o cientificismo.o entendimento de que os fenômenos comunicacionais devem ser explicados mediante o uso de procedimentos semelhantes aos da ciências da natureza. Embora combatida, essa ideologia domina pois a prática da comunicação é avaliada mediante processos quantitativos: raiting, ibopes, etc. As equações de custo/beneficio e lucratividade são eixos do cotidiano das empresas dos meios de comunicação.

i3 A tradição "cartorialista" do Brasil tem sido apontada como elemento de compreensão da regulação por parte do Estado das atividades profissionais.

14 Uso a expressão "aplicação" por ser consensual. De fato. a Comunicação Social é uma subárea das Ciências Sociais aplicadas, segundo o acordo comandado pelo CNPq.

${ }_{15}$ Nos cursos de comunicação não raro os teóricos são vistos com suspeita e, de modo geral, há uma valorização dos práticos. dos expertos. dos que estão com a mão na massal.

${ }^{16}$ O que denominamos habitualmente como teoria ou teorias da comunicação tem como eixo articulador a questão do impacto dos meios de comunicação a partir das contribuições teóricas da sociologia, da psicologia, filosofia e ciências políticas. Basicamente, tentou-se descrever e explicar o impacto, a influência dos meios de comunicação. Exemplos claros, embora com diferenças significativas, são as obras de: Meyrowitz. J., No sense of place, Oxford University Press. New York, 1985; DeFleur M.L., e Ball-Rokeach S., Teorias da comunicação de massa, Jorge Zahar Editor, Rio de Janeiro, 1993 (1989) e Thompson J. B.. A mídia c a modernidade, Rio de Janeiro, Ed. Vozes, 2001 (1995). 
${ }^{17}$ Ver o documento À comunidade dos Programas de Pós-Graduação em Comunicação, Hohlfeldt et alii, assinado por 6 coordenadores que circulou pela internet uma vez conhecidos os resultados da avaliação da CAPES no 2001.

${ }^{18} \mathrm{O}$ fato do currículo e da explicações serem de tipo mosaico em comunicação não significa que sejam intedisciplinares. Creio que estaríamos mais próximo dos processos reais se pensássemos em termos de trocas ou diálogos entre matrizes disciplinares. A distinção que se está discutindo resulta da relação de cada programa com a tradição. Se o que caracteriza à comunicação como área disciplinar é o estudo dos efeitos ou impactos da comunicação mediada o que se distancia da tradição pode ser colocado no posto de espera da fronteira.

${ }^{19}$ No documento se afirma que o consenso posto em questão sobre comunicação será tema em outubro do II Seminário Interprogramas de Pós-graduação em Comunicação. Prova suficiente da precariedade dos acordos da área.

${ }^{20}$ Tal tipo de definição pode circular melhor pela instâncias de agregação das áreas disciplinares no sistema de avaliação da CAPES. ${ }^{21}$ Observo que as cartas, uma das primeiras formas da comunicação mediada, foi um material privilegiado por historiadores e cientistas

140 sociais. A falta de registro das comunicações telefônicas fez difícil o estudo de tão importante recurso de comunicação mediada.

${ }^{22}$ Isto significa que a área deve parar de escolher pesquisadores pela sua formação em comunicação. A titulação não deve importar pois é um critério meramente formal. O significativo é o compromisso com a pesquisa na área que se expressa na produção e no conhecimento. Deixar de lado os arroubos corporativos é uma forma de desfazer o enredo da comunicação. 